\title{
Caregivers' knowledge and attitudes about childhood diarrhea among refugee and host communities in Gambella Region, Ethiopia
}

Getachew Kabew Mekonnen ${ }^{1,2^{*}}$, Bezatu Mengistie ${ }^{2}$, Geremew Sahilu', Worku Mulat ${ }^{3}$ and Helmut Kloos ${ }^{4}$

\begin{abstract}
Background: Maternal knowledge, attitudes, and practices related to hygiene, breastfeeding, sanitary food preparation, and appropriate weaning practices are potentially important determinants in the occurrence of diarrhea in children. However, few studies have been carried out about the knowledge and attitudes about childhood diarrhea among parents in refugee camps and host communities.

Objective: This study aims at assessing the caregivers' knowledge and attitudes regarding acute diarrhea in under-five children among refugee and host communities in Gambella Region, Ethiopia.

Methodology: This cross-sectional study, employing multistage sampling, was carried out from September to December 2016. Data was collected by a questionnaire-based interview, and 1667 caregivers were included in this study. A composite knowledge score was calculated, and a five-point Likert type of attitude scale was developed to assess the attitudes of the caregivers towards childhood diarrhea. Appropriate descriptive statistics and logistic regression models were used. Odds ratios (ORs) are presented with their 95\% confidence intervals (Cls), and all analyses were performed at the $5 \%$ significance level $(p<0.05)$.

Result: The study indicates that 633 (28.0\%) of the caregivers had poor knowledge, while 393 (23.6\%) of them had unfavorable attitudes towards childhood diarrhea. Knowledge of the caregivers was significantly associated with formal education (AOR, 1.3; $95 \% \mathrm{Cl}, 1.03-1.5)$ and health information obtained from a health care institution (AOR, 1.8; 95\% Cl, 1.28-2.3). Caregivers' knowledge is a single predictor of their attitude $(p<0.001)$, and Pearson's correlation coefficient revealed that there was a significant positive correlation $(r=0.2, p<0.001)$ between knowledge and attitude scores.

Conclusion: The study indicates that significant numbers of caregivers had inadequate knowledge and unfavorable attitudes about diarrhea in under-five children. Designing and implementing an inclusive health education intervention focusing on uneducated child caregivers may be beneficial for improving knowledge and attitudes towards reducing the incidence of acute childhood diarrhea in the region.
\end{abstract}

Keywords: Acute diarrhea, Knowledge, Attitudes, Under-five children, Refugees

\footnotetext{
* Correspondence: kabewgech@gmail.com

${ }^{1}$ Ethiopian Institute of Water Resources, Addis Ababa University, P.O. BOX.

150461, Addis Ababa, Ethiopia

${ }^{2}$ College of Health and Medical Sciences, Haramaya University, P.O. Box 1570,

Harar, Ethiopia

Full list of author information is available at the end of the article
}

(c) The Author(s). Open Access This article is distributed under the terms of the Creative Commons Attribution 4.0 International License (http://creativecommons.org/licenses/by/4.0/), which permits unrestricted use, distribution, and reproduction in any medium, provided you give appropriate credit to the original author(s) and the source, provide a link to the Creative Commons license, and indicate if changes were made. The Creative Commons Public Domain Dedication waiver (http://creativecommons.org/publicdomain/zero/1.0/) applies to the data made available in this article, unless otherwise stated. 


\section{Introduction}

Acute diarrhea is one of the most common causes of childhood morbidity and mortality in developing countries $[1,2]$. Diarrhea accounts for 760,000 deaths in children under 5 years of age worldwide, representing 15.2\% of all deaths among children less than 5 years of age in developing countries [3]. A high proportion of child morbidities and $25 \%$ of all deaths in refugee populations are due to diarrhea [4]. The majority (60-70\%) of diarrhea-related deaths are caused by dehydration due to loss of water and electrolytes [5]. The Integrated Management of Childhood Illness guidelines recommend the use of ORT along with continued feeding for appropriate diarrhea case management [6]. Recently, ORS fluid replacement accompanied by zinc treatment became the most successful approach [7], and appropriate antibiotics are also required to effectively treat bacterial diarrhea [8-10]. For these reasons, maternal knowledge and perceptions related to hygiene, breastfeeding, sanitary food preparation, and appropriate management and weaning practices are important determinants in the occurrence of diarrhea in children $[11,12]$. Mothers' basic knowledge about diarrhea depends on their educational status, their prior experience of managing the disease, and their culture, among others [13]. Mothers in marginalized communities have been found to have poor knowledge and attitudes about diarrhea in children [14]. Most mothers in one rural community did not recognize signs of dehydration due to diarrhea $[15,16]$, and many of them are unaware of fluid replacement or ORS use in treating diarrhea [17].

Since mothers are the chief caregivers of children, their socioeconomic condition significantly influences the health status of their children and outcome of diarrhea episodes [18]. Lack of caregivers' knowledge and awareness usually results in poor use of available information on preventing and managing childhood diarrhea in developing countries [19]. Caregivers' knowledge and attitudes are associated with socio-demographic conditions, culture, access to health education, and others $[13,20,21]$. Despite the universal popularity of oral rehydration solution in preventing child dehydration due to diarrhea, ORS is underutilized and incorrectly used, which usually resulted from the lack of mothers' knowledge [19] or perceptions of the seriousness of diarrhea [22]. Some studies showed that mothers have the intention to reduce and even stop fluids during diarrhea [23]. These attitudes and practices may be aligned to caregivers' knowledge and perceptions towards preventing childhood diarrhea [24]. Largely due to wide range of predisposing factors, diarrheal disease burden is not uniform in different regions of the world.

Diarrhea remains a major problem in refugee camps and rural communities in sub-Saharan Africa $[25,26]$.
The problem may be aggravated by political instability in countries where refugees originated, including South Sudan, Somalia, and Eritrea [27]. Hence, identifying knowledge gaps is critical for the development of effective preventive programs. To our knowledge, no formative studies previously have been undertaken on caregivers' knowledge and attitude about childhood diarrhea in refugee camps in Ethiopia. Thus, this study was aimed to assess caregivers' knowledge and attitude of caregivers regarding diarrhea in under-five children to generate pragmatic information in order to guide and influence public health policies in the region.

\section{Methodology}

\section{Study area and design}

The cross-sectional study was carried out from September to December 2016 in Pugnedo and Terkiedi refugee camps and the host in Gambella Region. Gambella is one of the 11 administrative regions of Ethiopia located along the Sudan border west of Addis Ababa. Multistage sampling was employed to select the study households. The objective of this study was to assess the caregivers' knowledge and attitudes regarding childhood diarrhea among refugee and host communities in Gambella Region, Ethiopia.

\section{Sample size determination}

The sample size was determined considering a $43 \%$ prevalence of diarrhea among children under five in internally displaced South Sudanese [28] and 31\% 2-week period prevalence of childhood diarrhea morbidity in rural communities in southwestern Ethiopia [29], representing the host communities, with $80 \%$ power, $95 \%$ confidence level, 1.5 design effect, and $10 \%$ non-response, and the final sample doubled the efficacy of a stratified community data analysis. The total sample size was determined to be 1782 (891 each from the refugee and host communities). The number of households with under-5-year-old children was 10,085 in Pugnido and 9,863 in Teirkidi refugee camps. Gog District, located near the refugee camps, was selected based on the potential to minimize confounding geographical factors. An equal number of study subjects were allocated to the two types of the communities, and samples were distributed proportionally to the size of the target population. Each household with under-5-year-old children was selected by systematic random sampling techniques (every 21st and 4th in the refugee and host communities, respectively).

\section{Data collection method}

This study was carried out among caregivers who had at least one under-five child; data were collected using a questionnaire during face-to-face interviews. The questions pertain to socio-demographic characteristics of households, 
caregivers' knowledge and attitudes about diarrhea, the predominant household drinking water source, availability of a latrine, and diarrheic condition of the child. It consisted of 13 open and closed questions and was divided into section $\mathrm{A}$, which had five multiple choice knowledge questions, and section $\mathrm{B}$, which had eight questions on attitudes.

The knowledge tool contained questions about the definition ( 1 point), causes ( 6 points), impacts ( 4 points), the management ( 8 points), and prevention ( 6 points) aspects of diarrhea. One point was given for each correct answer and a score of zero for wrong or uncertain answers. Each of the knowledge questions had one or more correct answers, and all questions had a total of 25 correct answers (or points). The caregivers' knowledge about diarrhea is indicated by the total points. A composite knowledge score was calculated, with higher scores indicating more correct answers. Mothers scoring above average were considered to have adequate knowledge, and mothers with a score below average were considered as having poor knowledge. The scores below 13, 13 to 19, and more than 19 were classified as low, average, and good knowledge, respectively.

The attitude questions covered caregivers' perceptions of a child contracting diarrhea regularly, preventing diarrhea by hand washing using water and soap, washing hands after toilet use, washing hands before eating, drinking clean water, exclusive breastfeeding, vaccination, and treating diarrhea with ORS. A five-point Likert type of attitude scale was developed to assess the attitudes of the caregivers towards childhood diarrhea. The scoring for each correct answer was given as: $1=$ strongly disagree, $2=$ disagree, $3=$ neutral, $4=$ agree, and $5=$ strongly agree. Negative scores were given for the incorrect answers. These eight attitude questions carried 8 to 40 points for each interviewee. Attitude scores less than 25 were classified as unfavorable, and scores 25 (50\%) and above were considered as favorable.

\section{Data quality control measures}

The questionnaire was developed in English language and then translated into the local Nuer and Agnwak languages for better communication with the study subjects. The recruited data collectors were those who completed at least their secondary education and are able to write, read, and understand English well. Training was given by the principal investigator a week before the onset of the study. Additionally, the questionnaire was pre-tested on 50 households of a similar community in the Jawi refugee camp, and necessary corrections were made accordingly. We checked the data onto consistency and completeness. The reliability test with Cronbach's alpha coefficient for the knowledge and attitude questions was 0.75 and 0.84 , respectively.

\section{Data analysis}

The responses were coded, entered, cleaned, and analyzed using STATA Version 14. Appropriate descriptive statistics such as mean, range, standard deviation, frequency, and percentages were calculated. Two sample $t$ test was used to compare the mean scores of knowledge and attitude between the two communities. Bivariate and multivariate logistic regression models were employed to identify factors influencing caregivers' knowledge and attitudes. Odds ratios (ORs) are presented with their 95\% confidence intervals (CIs), and all analyses were performed at the $5 \%$ significance level $(p<0.05)$.

\section{Operational definitions}

Knowledge: Caregivers' understanding about diarrhea definition, cause, common clinical sign and symptoms, disease outcomes, management, and prevention towards their under-five children.

Attitude: Caregivers' perception towards diarrhea among their under-five children.

Practice: Caregivers' action towards the management of diarrhea towards their under-five children.

Good knowledge: Those caregivers who answered more than $75 \%$ of the knowledge questions correctly were considered to have good knowledge.

Average knowledge: Those mothers/caregivers who answered between half (50\%) to three-fourth (75\%) of the knowledge questions were considered as good knowledge.

Poor knowledge: Those caregivers who answered less than $50 \%$ of the knowledge questions correctly were considered to have poor knowledge.

Adequate knowledge: Those caregivers who answered $50 \%$ or more of the knowledge questions correctly were considered to have adequate knowledge.

Favorable attitudes: Those caregivers whose mean scores were above or equal to $50 \%$ of the attitude questions.

Unfavorable attitudes: Those mothers who scored less than the mean scores were below $50 \%$ of the attitude questions.

\section{Results}

A total 1667 caregivers were interviewed and the response rate was $94 \%$. The median age of respondents was 28.4 years (range 15-60 years). Half (834) of the caregivers had not received any formal education, 509 (30.5\%) had attended primary school and 324 (19.4\%) completed at least secondary education. In this study, 596 (35.8\%) of under-five children had been ill with diarrhea during the 2 weeks prior to the survey and only 196 (32.9\%) had been seen in health institutions. Seven hundred (42.0\%) of the participants obtained health information about diarrhea in health care institutions, 563 
Table 1 Characteristics of the caregivers among refugee and host communities in Gambella Region, Ethiopia, 2016

\begin{tabular}{|c|c|c|c|c|}
\hline \multirow[t]{3}{*}{ Variable } & \multicolumn{2}{|c|}{ Refugee community } & \multicolumn{2}{|c|}{ Host community } \\
\hline & \multicolumn{2}{|c|}{$n=854$} & \multicolumn{2}{|c|}{$n=813$} \\
\hline & Freq. & $\%$ & Freq. & $\%$ \\
\hline \multicolumn{5}{|l|}{ Caregiver sex } \\
\hline Male & 46 & 5.4 & 23 & 2.8 \\
\hline Female & 808 & 94.6 & 790 & 97.2 \\
\hline \multicolumn{5}{|l|}{ Caregiver's age group (year) } \\
\hline$\leq 24$ & 232 & 27.2 & 263 & 32.4 \\
\hline $25-34$ & 447 & 52.3 & 436 & 53.6 \\
\hline$\geq 35$ & 175 & 20.5 & 114 & 14.0 \\
\hline \multicolumn{5}{|l|}{ Family size } \\
\hline$<5$ & 234 & 27.4 & 213 & 26.2 \\
\hline$\geq 5$ & 620 & 72.6 & 600 & 73.8 \\
\hline \multicolumn{5}{|l|}{ Caregiver's marital status } \\
\hline Married & 735 & 86.1 & 709 & 87.2 \\
\hline Single & 27 & 3.2 & 20 & 2.5 \\
\hline Divorced & 40 & 4.7 & 37 & 4.6 \\
\hline Widowed & 52 & 6.1 & 47 & 5.8 \\
\hline \multicolumn{5}{|l|}{ Ethnicity } \\
\hline Agnuak & 213 & 24.9 & 689 & 84.8 \\
\hline Nuer & 641 & 75.1 & 90 & 11.1 \\
\hline Others & - & - & 34 & 4.2 \\
\hline \multicolumn{5}{|l|}{ Caregiver education level } \\
\hline No formal education & 461 & 54.0 & 373 & 45.9 \\
\hline Primary school (grades 1 to 8 ) & 264 & 30.9 & 245 & 30.1 \\
\hline Secondary school (grades 9 to 12) & 63 & 7.4 & 113 & 13.9 \\
\hline Diploma and above & 66 & 7.7 & 82 & 10.1 \\
\hline \multicolumn{5}{|l|}{ Described diarrhea signs and symptoms } \\
\hline One sign or symptom & 310 & 36.3 & 259 & 31.9 \\
\hline Two signs or symptoms & 348 & 40.8 & 340 & 41.8 \\
\hline Three or more signs or symptoms & 140 & 16.4 & 155 & 19.1 \\
\hline Did not describe & 56 & 6.7 & 59 & 7.3 \\
\hline \multicolumn{5}{|l|}{ Usual source of health information } \\
\hline Health institutions & 358 & 41.9 & 342 & 42.1 \\
\hline Community health workers & 286 & 33.5 & 277 & 34.1 \\
\hline Schools & 35 & 4.1 & 21 & 2.6 \\
\hline Mass media (radio, TV) & 30 & 3.5 & 30 & 3.7 \\
\hline Do not know & 145 & 17.0 & 143 & 17.6 \\
\hline \multicolumn{5}{|c|}{ Health education attended within the last 3 months } \\
\hline Yes & 233 & 27.3 & 234 & 28.8 \\
\hline No & 378 & 44.3 & 352 & 43.3 \\
\hline Do not remember & 243 & 28.4 & 227 & 27.9 \\
\hline \multicolumn{5}{|l|}{ Health education topic attended last } \\
\hline HIV and other STDs & 56 & 23.7 & 70 & 29.8 \\
\hline Vaccination & 52 & 22.0 & 63 & 26.8 \\
\hline
\end{tabular}


Table 1 Characteristics of the caregivers among refugee and host communities in Gambella Region, Ethiopia, 2016 (Continued)

\begin{tabular}{|c|c|c|c|c|c|}
\hline \multirow[t]{3}{*}{ Variable } & & \multicolumn{2}{|c|}{ Refugee community } & \multirow{2}{*}{\multicolumn{2}{|c|}{$\begin{array}{l}\text { Host community } \\
n=813\end{array}$}} \\
\hline & & \multicolumn{2}{|c|}{$n=854$} & & \\
\hline & & Freq. & $\%$ & Freq. & $\%$ \\
\hline Child feeding & & 50 & 21.2 & 42 & 17.9 \\
\hline Diarrhea & & 46 & 19.5 & 32 & 13.6 \\
\hline WASH & & 26 & 11.0 & 17 & 7.2 \\
\hline Others & & 6 & 2.5 & 11 & 4.7 \\
\hline \multicolumn{6}{|l|}{ Outcome of diarrhea described } \\
\hline Not described & & 4 & 0.5 & 4 & 0.5 \\
\hline One outcome & & 116 & 13.6 & 92 & 11.2 \\
\hline Two or more outcome & & 734 & 85.9 & 717 & 88.2 \\
\hline \multicolumn{6}{|l|}{ Which treatments of diarrhea disease you know? } \\
\hline \multirow[t]{2}{*}{ Homemade fluids } & Yes & 83 & 9.7 & 44 & 5.4 \\
\hline & No & 771 & 90.3 & 769 & 94.6 \\
\hline \multirow[t]{2}{*}{ Oral rehydrating solution (ORS) } & Yes & 688 & 80.1 & 684 & 84.1 \\
\hline & No & 166 & 19.9 & 129 & 15.9 \\
\hline \multirow[t]{2}{*}{ Anti-diarrheal therapeutic medication such as antibiotics, Zn } & Yes & 401 & 47.0 & 331 & 40.7 \\
\hline & No & 453 & 53.0 & 482 & 59.3 \\
\hline \multirow[t]{2}{*}{ Herbal medicine } & Yes & 39 & 4.6 & 36 & 4.4 \\
\hline & No & 815 & 95.4 & 777 & 95.6 \\
\hline \multirow[t]{2}{*}{ Do not know } & Yes & 203 & 23.8 & 217 & 26.7 \\
\hline & No & 651 & 76.2 & 596 & 73.3 \\
\hline \multicolumn{6}{|l|}{ ORS preparation procedure described } \\
\hline Correct & & 268 & 31.4 & 195 & 24.0 \\
\hline Incorrect & & 586 & 68.6 & 618 & 76.0 \\
\hline \multicolumn{6}{|l|}{ Diarrhea prevention methods described } \\
\hline One & & 47 & 5.5 & 33 & 4.1 \\
\hline Two or more & & 803 & 94.0 & 775 & 95.3 \\
\hline None & & 4 & 0.5 & 5 & 0.6 \\
\hline
\end{tabular}

(33.8\%) from community health workers in their homes, and $60(3.6 \%)$ through mass media. Nearly one fifth, 288 (17.3\%), of the respondents never obtained health information from any external sources. Overall, 467 (28.0\%) of the participants had received some health education from health workers within the last 3 months prior to the survey. The topics attended were HIV and STI by $126(27.0 \%)$ caregivers, vaccination by 115 (24.6\%), child nutrition by $92(19.7 \%)$, diarrhea by $78(16.7 \%)$, and water, sanitation and hygiene (WASH) by 43 (9.1\%) caregivers, and 17 (3.6\%) of caregivers attended other topics (Table 1).

The overall mean knowledge score was $12.8 \pm 3.1$ (range 4-21). More than one third $(633,38.0 \%)$ of child caregivers had a low level of knowledge about diarrhea in under-five children. Out of 1034 (62.0\%) participants with adequate knowledge, 997 (59.8\%) had average knowledge while only 37 (2.2\%) had good knowledge of childhood diarrhea. Four hundred fifty-four (27.2\%) of the participants could properly define diarrhea. Nearly $34 \%$ (569) of the caregivers correctly identified one sign or symptom of diarrhea, followed by 688 (41.3\%) who described two and 295 (17.7\%) who listed three or more signs and symptoms. But 115 (6.9\%) of the participants had difficulties in recognizing signs and symptoms of diarrhea. More than 99\% (1656) of the caregivers explained at least one cause of diarrhea and 1333 (80.0\%) of them could describe three or more causes of diarrhea.

Nearly all (95.5\%) of child caregivers described a minimum of one undesirable outcome of diarrhea and 1452 (87.1\%) of them listed two or more of its consequences. One thousand three hundred seventy-two (82.3\%) of the respondents were familiar with ORS, 732 (43.9\%) of the caregivers knew that diarrhea can be treated with antibiotics, $127(7.6 \%)$ of them responded that it can be treated with homemade fluids, and 75 (4.5\%), with 
traditional medicine. However, only 463 (27.8\%) of the participants knew the correct ORS preparation procedure (one ORS sachet to $1 \mathrm{~L}$ of water) and $574(34.4 \%)$ of them knew that prepared ORS should be discarded after 24h. Moreover, 1578 (94.7\%) of the respondents knew two or more ways of diarrhea prevention in under-five children.

The overall mean attitude score of the caregivers was $28.2 \pm 5.1$ (range 14-37). The majority (1274, 76.4\%) of the respondents had a favorable attitude, and 393 (23.6\%) had an unfavorable attitude on childhood diarrhea. About 22\% (374) believed that diarrhea is normal in children. The middle proportion $(916,54.9 \%)$ of the study participants either strongly agreed or agreed that exclusive breastfeeding is important in preventing childhood diarrhea (Table 2).

Variables with $p$ value $\leq 0.25$ in bivariate analysis were carried on and few of them appeared to be the independent predictors in the multivariate logistic model. Factors such as gender, age, and marital status were not associated with participants' knowledge and attitudes. Knowledge was statistically higher among caregivers who had formal education (AOR, 1.3; 95\% CI, 1.03-1.5) and obtained health information from a health care institution (AOR, 1.8; 95\% CI, 1.28-2.3) compared to those who never accessed formal education and health education, respectively. Caregivers' knowledge had an association with their attitude about diarrhea in under-five children (AOR, 2.5; 95\% CI 1.6-3.8) (Table 3). Pearson's correlation coefficient revealed that there was a positive correlation $(r=0.2, p<0.001)$ between knowledge and attitude scores. The independent $t$ test also showed that there were no statistically significant differences in mean knowledge $(t=0.18)$ and attitude $(t=0.88)$ scores between the two communities.

\section{Discussion}

Caregiver's knowledge and attitude regarding causes, sign and symptoms, management, prevention, and control are very essential in reducing child morbidity and mortality due to diarrhea. So, assessing caregiver's knowledge and attitude would be helpful in designing an effective health education strategy towards empowering them. This study revealed that more than one third (38\%) of the caregivers had poor knowledge about childhood diarrhea, in both the refugee and host communities. This finding is in line with similar studies [30-32]. Caregivers with formal education $(p=0.022)$ had $30 \%$ better knowledge than those with no formal education. These findings are incongruent with a study done in Bangladesh [33] and in agreement with others [30]. This may be due to the fact that education augments parents' knowledge of diarrhea [13, 34]. Only $27.2 \%$ of the caregivers could define diarrhea, less than those in studies in India, Iran, and Bangladesh [35-37]. This discrepancy may be due to different socioeconomic factors among study the participants. Nevertheless, the overall findings are similar to those of other studies $[15,38]$. This could be due to the fact that half (50\%) of the studied caregivers had no formal education and thus might have limited knowledge about diarrhea.

About $66 \%$ of them explained two or more symptoms of diarrhea. Majority (99.4\%) of the caregivers could describe at least one cause of diarrhea that was similar with a study done in India [39]. The most commonly mentioned causes were eating unhygienic food 703 (42.2\%) followed by eating with contaminated hands $621(37.3 \%)$ and germs 141 (8.5\%). Out of 596 diarrheic children, only 196 (32.9\%) were taken by their caregivers to health facilities. Parents with poor knowledge

Table 2 Caregivers' attitudes about diarrhea in under-five children in refugee and host communities in Gambella Region, Ethiopia, 2016

\begin{tabular}{|c|c|c|c|c|c|}
\hline \multirow[t]{2}{*}{ Variable } & \multicolumn{5}{|l|}{$N=1667(\%)$} \\
\hline & Strongly disagree & Disagree & Undecided & Agree & Strongly agree \\
\hline $\begin{array}{l}\text { Do you think that it is normal for children to get } \\
\text { diarrhea regularly? }\end{array}$ & $311(18.7)$ & $630(37.8)$ & $352(21.1)$ & $328(19.7)$ & $46(2.8)$ \\
\hline $\begin{array}{l}\text { Do you think that hand washing with water and } \\
\text { soap prevents diarrhea? }\end{array}$ & $19(1.1)$ & $163(9.8)$ & $564(33.8)$ & $732(43.9)$ & $189(11.3)$ \\
\hline $\begin{array}{l}\text { Do you think that hand washing before eating or } \\
\text { feeding your child prevents diarrhea? }\end{array}$ & $35(2.1)$ & $103(6.2)$ & $662(39.7)$ & $726(43.6)$ & $141(8.5)$ \\
\hline $\begin{array}{l}\text { Do you think that hand washing after toilet or } \\
\text { cleaning the child's bottom prevent diarrhea? }\end{array}$ & $13(0.8)$ & $269(16.1)$ & $454(27.2)$ & $804(48.2)$ & $127(7.6)$ \\
\hline $\begin{array}{l}\text { Do you think that drinking clean water is important } \\
\text { for the prevention of diarrhea? }\end{array}$ & $11(0.7)$ & $257(15.4)$ & $389(23.3)$ & $725(43.5)$ & $285(17.1)$ \\
\hline Do you think that diarrhea can be treated with ORS? & $16(1.0)$ & $157(9.4)$ & $606(36.4)$ & $787(47.2)$ & $101(6.1)$ \\
\hline $\begin{array}{l}\text { Do you think that exclusive breastfeeding prevents } \\
\text { diarrhea in children less than } 6 \text { months old? }\end{array}$ & $17(1.0)$ & $102(6.1)$ & $632(37.9)$ & $717(43.0)$ & 199 (11.9) \\
\hline Do you think that vaccination is harmful for children? & $235(14.1)$ & $745(44.7)$ & $333(20.0)$ & $301(18.1)$ & $53(3.2)$ \\
\hline
\end{tabular}




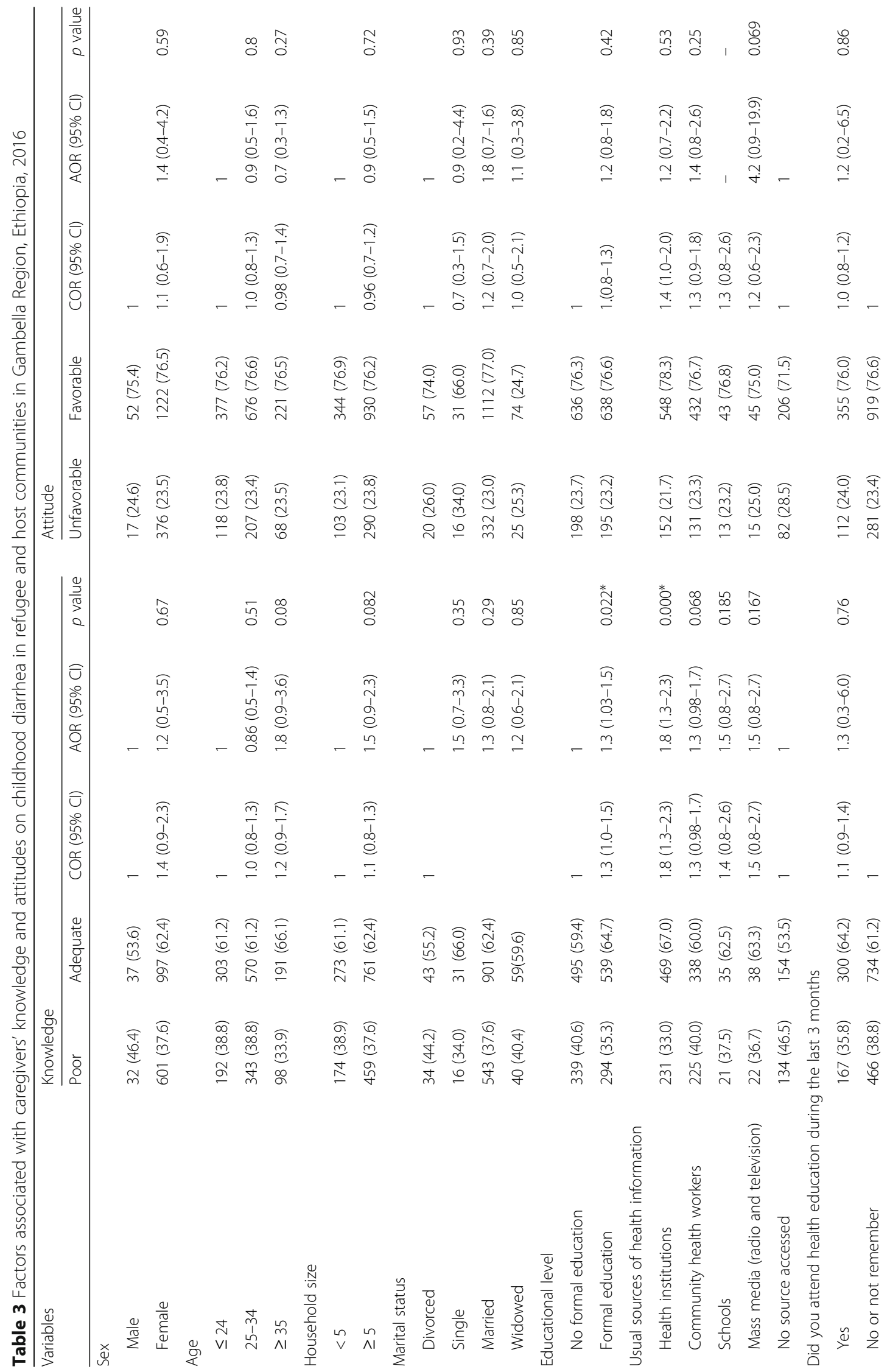




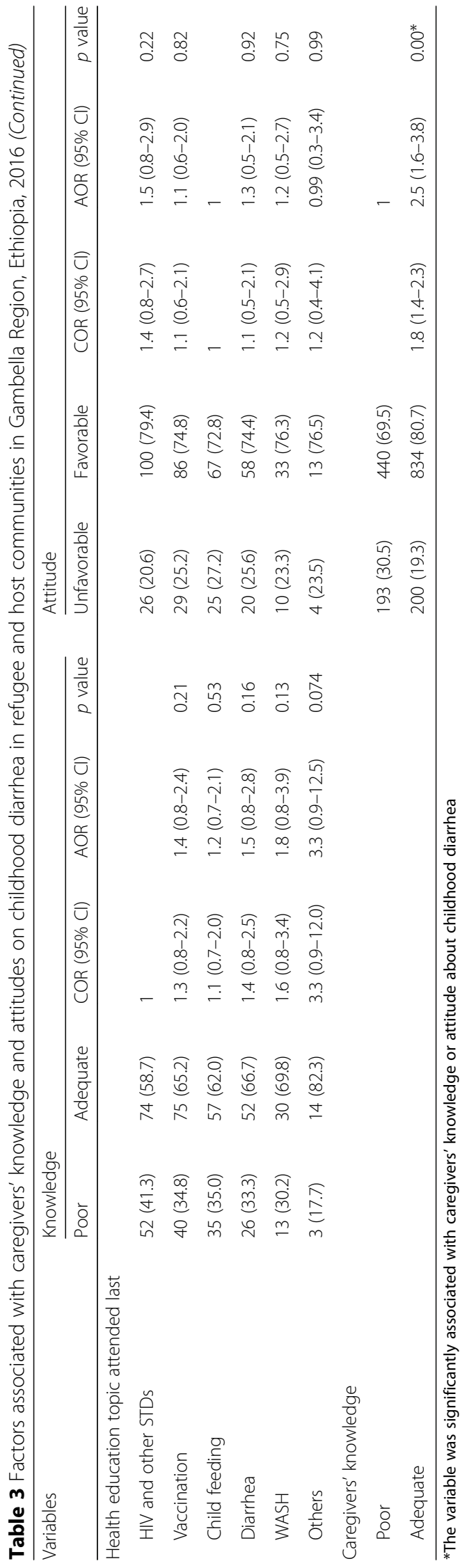


are unlikely to go to hospitals because there is a positive association between knowledge and care-seeking behavior [40]. The percentage of caregivers who knew home-based fluids for treating diarrhea was very low in similar studies from other developing countries [41].

Although most of the participants were aware of ORS, our study reveals that there was poor knowledge of ORS preparation (26.4\%) and its use (33.2\%). This inferior knowledge of ORS preparation is in line with a study done in Nepal $[14,36]$ and contrasts with other studies [42, 43]. Nearly all $(1578,94.7 \%)$ of the caregivers knew two or more methods of prevention of diarrhea, more than those reported by other studies [37]. Caregivers who often obtained health information from health care institutions $(p<0.001)$ were 1.8 times more likely to have adequate knowledge than those who heard nothing about childhood diarrhea. This is due to the fact that health education improves human behavior and life style [44].

Our results also showed that a majority of the study participants had a favorable attitude against diarrhea, which is in agreement with other similar studies [45]. A considerable proportion $(22.4 \%)$ of the caregivers perceived diarrhea to be a normal phenomenon occurring in growing children, which is in agreement with studies done in similar rural settings [21]. These wrong beliefs may reflect community culture in diarrhea prevention [46-49]. Nearly $17.7 \%$ of child caregivers considered that hand washing after using the toilet or cleaning a child's bottom was not relevant to preventing diarrhea. Only one fourth of the caregivers believed that vaccination may be harmful to their child, as also reported by a study in India [50]. This may be due to lack of knowledge [51]. We found that caregivers' attitude is significantly associated with their level of knowledge $(p<0.001)$ which is in turn affected by education, as caregivers who were highly literate were better informed about preventive practices. These findings are in agreement with the views by Rasania et al. and Bachrach and Gardner [43].

\section{Conclusion and recommendations}

The mean knowledge and attitude scores among the two communities were analogous. The findings of this study indicate that significant numbers of caregivers had inadequate knowledge while some had unfavorable attitudes about diarrhea occurring in under-five children. Health promotion programs focusing on enhancing maternal knowledge and attitudes might have a protective effect on diarrhea and facilitate its management. Thus, designing and implementing an inclusive health education intervention focusing on uneducated child caregivers may be beneficial in improving their knowledge and attitudes towards lessening acute childhood diarrhea in such communities.

\section{Abbreviations}

ARRA: Administration for Refugees and Returnees Affairs; UNHCR: United Nations High Commissioner for Refugees; WASH: Water, sanitation and hygiene

\section{Acknowledgements}

We would like to express our deepest gratitude to the Ethiopian Administration for Refugee and Returnee Affairs, the UNHCR, and the International Rescue Committee and Gambella Regional Health Bureau for their valuable support during the field work. We would also like to acknowledge the staff of the health facilities in the refugee camps and Gog District Health Office for their kind cooperation and assistance. We also extend our gratitude to the study households for participating in this study and the data collectors and field supervisors for contributing their time and insights.

\section{Funding}

This PhD research was funded by the Ethiopian Institute of Water Resources, Addis Ababa University, as a PhD student research fund, ID. GSR/080/07.

\section{Availability of data and materials}

The relevant data supporting this publication are summarized in the tables in the manuscript. However, the raw data can be accessed from the principal author (GK) whenever required using appropriate procedures and format.

\section{Authors' contributions}

The principal investigator, GK, collected and analyzed the data. BM, GS, WM, and HK were directing and supervising the research process. All authors contributed to designing the proposal, drafting the manuscript, and approving the final version to be manuscript for publication. The supporting data for this study are available from the corresponding author upon request.

\section{Ethics approval and consent to participate}

The study was reviewed and approved by the Ethiopian National Research Ethics Review Committee. Letters were written by the Ethiopian Institute of water Resources in Addis Ababa University to the Ethiopian Administration for Refugees and Returnees Affairs (ARRA) and the UNHCR to obtain permission and support related to our research work. Written informed consent was obtained from caregivers. Interviews were ensured that their participation was voluntary and the information they provided was kept confidential.

\section{Consent for publication}

Not applicable

\section{Competing interests}

The authors declare that they have no competing interests.

\section{Publisher's Note}

Springer Nature remains neutral with regard to jurisdictional claims in published maps and institutional affiliations.

\section{Author details}

${ }^{1}$ Ethiopian Institute of Water Resources, Addis Ababa University, P.O. BOX. 150461, Addis Ababa, Ethiopia. ${ }^{2}$ College of Health and Medical Sciences, Haramaya University, P.O. Box 1570, Harar, Ethiopia. ${ }^{3}$ Department of Civil and Environmental Engineering, University of Connecticut, Storrs, CT, USA. ${ }^{4}$ Department of Epidemiology and Biostatistics, University of California, San Francisco, CA, USA.

Received: 6 September 2018 Accepted: 6 November 2018

Published online: 22 November 2018

\section{References}

1. Strina A, Cairncross S, Prado MS, Teles CA, Barreto ML. Childhood diarrhoea symptoms, management and duration: observations from a longitudinal community study. Trans R Soc Trop Med Hyg. 2005;99:407-16.

2. Geldsetzer P, Williams TC, Kirolos A, Mitchell S, Ratcliffe LA, Kohli-Lynch MK, Bischoff EJL, Cameron S, Campbell H. The recognition of and care seeking behaviour for childhood illness in developing countries: a systematic review. PLoS One. 2014;9:e93427. 
3. WHO: Diarrheal disease. WHO. Media Centre. Fact sheet N³30. Available at: http://www.who.int/news-room/fact-sheets/detail/diarrhoeal-disease. Accessed 21 Apr 2018.

4. JH: Public health guide for emergencies. Chapter, 8:372-381. Available at: https://quizlet.com/256398151/chapter-8-study-guide-emergency-care-firstaid-and-disasters-flash-cards/. Accessed 20 Apr 2018.

5. Zwisler G, Simpson E, Moodley M. Treatment of diarrhea in young children: results from surveys on the perception and use of oral rehydration solutions, antibiotics, and other therapies in India and Kenya. J Glob Health. 2013;3(1):010403. https://doi.org/10.7189/jogh.03.010403.

6. WHO: A Handbook IMCl: integrated management of childhood illness: World Health Organization; 2005. Available at: http://www.who.int/iris/ handle/10665/42939. Accessed 15 Nov 2018.

7. Walker CLF, Black RE. Zinc for the treatment of diarrhoea: effect on diarrhoea morbidity, mortality and incidence of future episodes. Int J Epidemiol. 2010;39: i63-9.

8. Wiström J, Jertborn M, Ekwall E, Norlin K, Söderquist B, Strömberg A Lundholm R, Hogevik H, Lagergren L, Englund G. Empiric treatment of acute diarrheal disease with norfloxacin: a randomized, placebo-controlled study. Ann Intern Med. 1992;117:202-8.

9. Thielman NM, Guerrant RL. Acute infectious diarrhea. N Engl J Med. 2004; 350:38-47.

10. Leibovitz E, Janco J, Piglansky L, Press J, Yagupsky P, Reinhart H, Yaniv I, Dagan R. Oral ciprofloxacin vs. intramuscular ceftriaxone as empiric treatment of acute invasive diarrhea in children. Pediatr Infect Dis J. 2000;19:1060-7.

11. Mock NB, Sellers TA, Abdoh AA, Franklin RR. Socioeconomic, environmental, demographic and behavioral factors associated with occurrence of diarrhea in young children in the Republic of Congo. Soc Sci Med. 1993;36:807-16.

12. Manun'ebo MN, Haggerty PA, Gaie MK, Ashworth A, Kirkwood BR. Influence of demographic, socioeconomic and. J Trop Med Hygiene. 1994; 97:31-8.

13. Anidi I, Bazargan M, James FW. Knowledge and management of diarrhea among underserved minority parents/caregivers. Ambul Pediatr. 2002;2:201-6.

14. Mukhtar A, Izham MIM, Pathiyil RS. A survey of mothers' knowledge about childhood diarrhoea and its management among a marginalised community of Morang, Nepal. Australas Med J. 2011;4:474.

15. Delgado MF, Sierra CH, Calvache JA, Ríos ÁM, Mosquera C, Salas I, Agredo F, Meneses R. Maternal knowledge about children s danger signs in acute diarrhoea in an IMCI s frame. Colombia Médica. 2006:37:293-8.

16. Gupta N, Jain S, Chawla U, Hossain S, Venkatesh S. An evaluation of diarrheal diseases and acute respiratory infections control programmes in a Delhi slum. Indian J Pediatrics. 2007:74:471-6.

17. Othero DM, Orago AS, Groenewegen T, Kaseje DO, Otengah P. Home management of diarrhea among underfives in a rural community in Kenya: household perceptions and practices. East Afr J Public Health. 2008;5(3): 142-6.

18. Mutalik AV, Raje W. Relationship between maternal education and socioeconomic status on knowledge, attitude and practice of mother and her child regarding acute diarrhoeal diseases. Int J Commun Med Public Health. 2017:4:4472-6.

19. Bhatnagar S, Alam S, Gupta P. Management of acute diarrhea: from evidence to policy. Indian Pediatr. 2010;47:215-7.

20. Katung P. Socio-economic factors responsible for poor utilisation of the primary health care services in a rural community in Nigeria. Niger J Med. 2001;10:28-9.

21. Mwambete K, Joseph R. Knowledge and perception of mothers and caregivers on childhood diarrhoea and its management in Temeke municipality, Tanzania. Tanzania J Health Res. 2010;12:47-54.

22. Oshikoya K, Njokanma O, Bello J, Ayorinde E. Family self-medication for children in an urban area of Nigeria. Paediatric Perinatal Drug Ther. 2007:8:124.

23. Berisha M, Hoxha-Gashi S, Gashi M, Ramadani N. Maternal practice on management of acute diarrhea among children under five years old in Kosova. F Prev Med Bull. 2009;8(5):369-372.

24. Grimwood K, Forbes DA. Acute and persistent diarrhea. Pediatr Clin. 2009; 56:1343-61.

25. Hershey CL, Doocy S, Anderson J, Haskew C, Spiegel P, Moss WJ. Incidence and risk factors for malaria, pneumonia and diarrhea in children under 5 in UNHCR refugee camps: a retrospective study. Confl Heal. 2011;5:24.

26. Fletcher SM, Stark D, Ellis J. Prevalence of gastrointestinal pathogens in SubSaharan Africa: systematic review and meta-analysis. J Public Health Africa. 2011;2(2):e30.
27. UNHCR: Responding to Refugee Crisis; 2017. Available at: https:// interagencystandingcommittee.org/system/files/ethipia_and_uganda_responding_to_refugee_crisis___lessons_from_evaluations_in_ethiopia_ and_uganda_as_countries_of_destination_.pdf. Accessed 14 Nov 2018.

28. THWOL ET: Academic Article Prevalence of Diarrhea and Malaria among Under Five Years Children in Rubkona IDPs; 2015. Available at: https:// pachodo.org/latest-news-articles/pachodo-english-articles/10757-academicarticle-prevalence-of-diarrhea-and-malaria-among-under-five-years-childrenin-rubkona-idps. Accessed 10 Nov 2017.

29. Mohammed S, Tilahun M, Tamiru D. Morbidity and associated factors of diarrheal diseases among under five children in Arba-Minch district, Southern Ethiopia, 2012. Sci J Public Health. 2013;1:102-6.

30. Amare D, Dereje B, Kassie B, Tessema M, Mullu G, Alene B, Ayele A. Maternal knowledge and practice towards diarrhoea management in under five children in fenote selam town, west gojjam zone, Amhara regional state, Northwest Ethiopia. J Infect Dis Ther. 2014;2:182. https://doi.org/10.4172/ 2332-0877.1000182

31. Khalili M, Mirshahi M, Zarghami A, Rajabnia M, Farahmand F. Maternal knowledge and practice regarding childhood diarrhea and diet in Zahedan, Iran. Health Scope. 2013;2:19-24.

32. Zafar M. Knowledge and attitude towards and preventive practices relating to diarrhea among mothers under five years of children: findings of a crosssectional study in Karachi. Pakistan J Infect Dis Ther. 2014;2:1-6.

33. Wahed T, Kaukab SST, Saha NC, Khan IA, Khanam F, Chowdhury F, Saha A, Khan Al, Siddik AU, Cravioto A. Knowledge of, attitudes toward, and preventive practices relating to cholera and oral cholera vaccine among urban high-risk groups: findings of a cross-sectional study in Dhaka, Bangladesh. BMC Public Health. 2013;13:242

34. Mangala S, Gopinath D, Narasimhamurthy N, Shivaram C. Impact of educational intervention on knowledge of mothers regarding home management of diarrhoea. Indian J Pediatrics. 2001;68:393-7.

35. Abdinia B. Knowledge and practice of mothers in the management of children's diarrhea, in Northwest, Iran. Arch Pediatr. 2014;2:e17581.

36. Padhy S, Sethi RK, Behera N. Mother's knowledge, attitude and practice regarding prevention and management of diarrhoea in children in Southern Odisha. Int J Contemp Pediatrics. 2017:4:966-71.

37. Hackett KM, Mukta US, Jalal CS, Sellen DW. Knowledge, attitudes and perceptions on infant and young child nutrition and feeding among adolescent girls and young mothers in rural Bangladesh. Matern Child Nutr. 2015;11:173-89.

38. Bachrach LR, Gardner JM. Caregiver knowledge, attitudes, and practices regarding childhood diarrhea and dehydration in Kingston, Jamaica. Rev Panam Salud Publica. 2002;12:37-44.

39. Saurabh S, Shidam UG, Sinnakirouchenan M, Subair M, Hou LG, Roy G Knowledge and practice regarding oral rehydration therapy for acute diarrhoea among mothers of under-five children in an urban area of Puducherry India. Natl J Community Med. 2014;5:100-4.

40. Noordam AC, Sharkey AB, Hinssen P, Dinant G, Cals JW. Association between caregivers' knowledge and care seeking behaviour for children with symptoms of pneumonia in six sub-Saharan African countries. BMC Health Serv Res. 2017;17:107.

41. Shah MS, Ahmad A, Khalique N, Afzal S, Ansari MA, Khan Z. Home-based management of acute diarrhoeal disease in an urban slum of Aligarh, India. J Infect Dev Countries. 2011;6:137-42.

42. Jha N, Singh R, Baral D. Knowledge, attitude and practices of mothers regarding home management of acute diarrhoea in Sunsari, Nepal. Nepal Med Coll J. 2006:8:27-30

43. Rasania S, Singh D, Pathi S, Matta S, Singh S. Knowledge and attitude of mothers about oral rehydration solution in few urban slum of Delhi. Health Popul Perspect Issues. 2005;28:100-7.

44. Maramagi CA, Lubanga RG, Kiguli S, Ekwaru PJ, Heggenhougen K. Health providers' counselling of caregivers in the Integrated Management of Childhood IIIness (IMCI) programme in Uganda. Afr Health Sci. 2004:4:31-9

45. Mathiazhakan U. A study to assess the knowledge, attitude and practice of caregivers of children admitted with diarrhoea at KMCH Hospital, Coimbatore. Int J Pharmacy Biol Sci. 2016;6:16-22.

46. Mull JD, Mull DS. Mothers' concepts of childhood diarrhea in rural Pakistan: what ORT program planners should know. Soc Sci Med. 1988;27:53-67.

47. Choprapawon C, Chunsutiwat S, Kachondham Y, Weiss MG. Cultural study of diarrhoeal illnesses in Central Thailand and its practical implications. Diarrhoeal Dis Res. 1991;9(3):204-212. 
48. Smith GD, Gorter A, Hoppenbrouwer J, Sweep A, Perez RM, Gonzales C, Morales P, Pauw J, Sandiford P. The cultural construction of childhood diarrhoea in rural Nicaragua: relevance for epidemiology and health promotion. Soc Sci Med. 1993:36:1613-24.

49. Sodemann M, Jakobsen M, Mølbak K, Martins C, Aaby P. Maternal perception of cause, signs and severity of diarrhoea in a suburban West African community. Acta Paediatr. 1996;85:1062-9.

50. Mukherjee S, Madhivanan P, Li T, Albatineh A, Srinivas V, Jaykrishna P, Arun A, Krupp K. Correlates of completing routine vaccination among children in Mysore, India. J Infect Public Health. 2015;8:62-71.

51. Velandia-González M, Trumbo SP, Pedreira MC, Bravo-Alcántara P, DanovaroHolliday MC. Understanding the main barriers to immunization in Colombia to better tailor communication strategies. BMC Public Health. 2014;14:669.

Ready to submit your research? Choose BMC and benefit from:

- fast, convenient online submission

- thorough peer review by experienced researchers in your field

- rapid publication on acceptance

- support for research data, including large and complex data types

- gold Open Access which fosters wider collaboration and increased citations

- maximum visibility for your research: over $100 \mathrm{M}$ website views per year

At $\mathrm{BMC}$, research is always in progress.

Learn more biomedcentral.com/submissions 